\title{
Proposing a Managerial Model to Higher Education Sector: Lifelong Educational Experiences of Overseas Students on Impediments
}

\author{
Ali Erden \\ Educational Sciences Faculty, Cyprus Social Sciences University, Turkey
}

Copyright $C 2017$ by authors, all rights reserved. Authors agree that this article remains permanently open access under the terms of the Creative Commons Attribution License 4.0 International License

\begin{abstract}
Lifelong education is a process including positive and negative experiences at the same time. Negative experiences mostly appear as impediments to the overseas students. They need to overcome impediments they experience throughout their education. The paper discussed the key findings of a two-year research project for identifying the impediments and their frequency faced in the higher education sector and for proposing a managerial model. This case study adopted a descriptive methodology under qualitative research paradigm. Data were collected through focus-group-interviews (FGIs) and in-depth-interviews (I-DIs). Focus-group-members (FGMs) were 50 -OSs studying various departments and various universities in NC. I-DIs were taken place with 75-different-overseas-university-students (dOSs) studying at various departments of universities in NC. The impediments are identified on mobility, adaptation, internationalization and maturation which are strongly affected by the feelings and affections, changes, irregularities and barriers. The managerial model is based on managing accommodation and transportation; managing studentship; managing student health; managing students' welfare and managing being worldwide.
\end{abstract}

Keywords Educational Lifelong Experiences, Impediments, Managerial Model, Overseas Students

\section{Introduction}

The current research paper explores the findings of a two-year research project, which inquired into the experiences of overseas undergraduate and graduate students at five universities in North Cyprus. The research reported the censorious effects on overseas students' mobility, intercultural adaptation, internationalization and maturation investigated how these effects influenced them during their stay in North Cyprus and proposed a managerial model on impediments and frequency of impediments OSs face throughout their higher education studies in NC. Experiencing and/or even having sense of negative experiences, hindrances and/or obstructions causing failure to progress of the students are considered as impediments to the overseas students.

Impediments to higher education sector have been defined as the hindrance or obstruction (Oxford Dictionaries, n.d) on educational experiences of university students from abroad as part of their lifelong learning. Impediments may block progress and/or development of the overseas students. Therefore, it is worth to describe the impediments and frequency of impediments for overseas students to be able to plan, facilitate, make progress and maintain development of the students in terms of their lifelong learning. There were 47,070 students from Turkey in $\mathrm{NC}$ and 27,139 students from other countries and at fall semester in 2016-2017 academic year. The ratio of whole population of university students in $\mathrm{NC}$ (population of students from North Cyprus, as well as population of students from Turkey and from other countries which were named as the overseas students) to overseas students was $49,5 \%$ in the abovementioned academic year (The Higher Education Department of Ministry of National Education and Culture, personal communication, September 11, 2017).

Intercultural experience has included both national and international contexts and has suggested interaction of cultures (King and Baxter Magolda, 2005). Intercultural experience as a process for transforming learning gives rise to growing and developing personally (Anderson, 1994; Furnham, 2004). As overseas students are exposed to different cultures and different cultural environments, as well as meet different people due to the exposure of the culture and its environment, they may adapt to become of the member of the culture, the environment and may behave like the people they meet in a gradual way. On the 
other hand, overseas students may not feel to modify their certain aspects of their cultural beliefs and values $(\mathrm{Gu}$, Schweisfurth and Day, 2010), therefore they may not integrate and abandon for the recent culture, environment and people they have met (Paulston, 1992; Byram, 2003) and may develop their way of expression to meet their social needs (Kim, 2005). Overseas students react to intercultural stress through adjusting psychologically and adapting socio-culturally (Leung, Pe-Puab and Kamilowicz, 2006; Li and Gassner, 2005; Mori, 2000; Ward and Kennedy, 1993; Ward and Kennedy, 1996).

On the other hand, lifelong learning is a process covering institutional fact. Social institutions promote lifelong learning rather than the individual (Billett, 2010). Lifelong education and higher education has close relationship and cover three levels which are learning process, creating learner's identities and having perception the connection between learning and the wider world (Brooks and Everett, 2008). The current study has contributed to describing the perceptions of overseas students regarding their university-life quality in NC. Their lifelong experiences give rise to describe impediments they experience and offer a managerial model to higher education sector. Lifelong education covers both pre-service and in-service education. In this sense, the study has been important for the higher education sector being able to plan and improve the life quality of overseas students. Similarly, it enables and demands educators as well as higher education institutions to value intercultural experiences of both local and foreign students in NC. Importance of proposing a managerial model by identifying the intercultural experiences of overseas students regarding factors and frequency of factors contributing to impediments throughout their undergraduate and graduate lives in a foreign context is considered importance because a management model is an act of opportunity to make choices. In this sense, OSs can be able to make their sets of choices on how they were managed in NC. In a managing model, key stakeholders of the higher education sector, including members of Ministry of Education, committee members from Higher Education Planning, Supervision, Accreditation and Coordination Committee, and managers at universities, need to define their objectives, motivate the effort, coordinate activities in harmony and distribute the resources in balanced in the higher education sector. Realizing its aim, this study has sought answers to the following research question:

What do the overseas students report about impediments and frequency of impediments they face throughout their university-lives in $\mathrm{NC}$ ?

\section{Method}

The current study has aimed at describing the perceptions of overseas students studying at various departments at various universities in Northern Cyprus on impediments and frequency of impediments for proposing a managerial model to higher education sector. It adopted a descriptive methodology. Under qualitative paradigm, case study has been used as the research design.

\section{Participants}

50 focus group members (50-FGMs) participated to the focus group interviews (FGIs). 75-in-depth-interviewers participated to the in-depth interviews (I-DIs). FGMs were OSs from various grades, various departments and various universities in NC. 10-Overseas-university-students from University-1(10-OSsfU1); 10-OSsfU2; 10-OSsfU3; 10-OSsfU4; and 10-OSsfU5 participated to the study. I-DIs were conducted with $75-\mathrm{dOSs}$ to make sure that identified factors contributing to impediments were common. 15-dOSsfU1 different-overseas-university-students from University-1(dOSsfU1); 15-dOSsfU2; 15-dOSsfU3; 15-dOSsfU4; and 15-dOSsfU5 participated to the second phase of the study to identify the common impediments. Then, the perceptions of OSs were identified regarding frequency of factors contributing to impediments throughout their university lives in NC using FGIs, which were conducted to the initial 50-FGMs(OSsfU1-OSsfU5). Semi-structured interview form-1 for FGMs, OSsfU1-OSsfU5 were produced and implemented to identify the perceptions of OSs regarding factors contributing to impediments throughout university lives of them in NC.

After identification of factors contributing to impediments, unstructured interview form-1 for participants called dOSsfU1-dOSsfU5, were produced and implemented to identify perceptions of OSs regarding common factors contributing to impediments throughout university lives of them in NC. Throughout the process, data analysis results of FGIs and I-DIs were compared and then common points were regarded as common impediments.

Then, frequency of each common impediment was identified through FGIs with OSsfU1-OSsfU5 to find out the frequency of factors contributing to impediments throughout university lives of OSs in NC.

Interpretive approach was used for qualitative data collection. Semi-structured-interviews and I-DIs were applied as part of data collection methods. Data collected through interpretive approach were analyzed using content analysis method. Content analysis includes identifying, coding, categorizing, classifying and labeling the main occurring themes in the data (Miles \& Huberman 1994; Patton, 2002).

\section{Trustworthiness}

The experts in the field of educational sciences reviewed 
research instruments and data each time. Based on the reviewers' comments, the ambiguous and uncertain questions were redesigned and the complex/unclear items were re-worded for enhancing content validity. Also, the ineffective and non-functioning questions were either removed or re-shaped. Also, these experts face validated the questions. The dependability of the results obtained from the data using the open-ended and semi-structured interview forms were provided through the use of the techniques called the investigator's position, triangulation and audit trial (Lincoln \& Guba, 1985). For the current study, the-status-of-the-researcher (as an instructor, researcher's social position increased the possibility of reaching the most appropriate participants) and the-choice-of-informants (the researcher described the participants clearly; therefore, any independent researcher who might desire to replicate the study, could do it very easily) and the-social-situations-and-conditions (the study was conducted in academic environments and situation. Therefore, the social situation and condition was fairly constant and uniform to the participants); the-analytic-constructs-and-premises (main terms, constructs, definitions, units of analysis and premises were delineated and their underlying assumptions were elaborated explicitly) and the-methods-of-data-collection-and-analysis (data were collected using semi-structured and unstructured interview forms. Methods and thematic interpretations were explored clearly) were applied for managing the external reliability) (Zohrabi, 2013). Also, internal reliability for the present study has been elaborated using low inference descriptors (it is difficult to observe factors contributing to factors and frequency of identified factors impeding OSs' university lives in NC. Elaborated descriptions and explanations by OSsfU1-OSsfU5 and dOSsfU1-dOSsfU5 enhance the internal reliability and any independent researchers/observer any time can observe and replicate these factors rather easily) and having mechanically recorded data (the interviews were recorded and preserved. Any independent researcher can easily implement the reanalysis or replication of the data) (Nunan, 1999).

\section{Findings}

The research revealed the factors contributing to factors impeding overseas students and frequency of these impediments throughout their undergraduate and graduate studies in NC in terms of their learning in an academic environment, their adaptation to the cultural and academic environment and their personal growth. Key findings were given under 4 related themes: (1) Mobility, (2) Adaptation, (3) Internationalization, and (4) Maturation. Each theme was affected by sub-themes called (i) Feelings and Affections, (ii) Changes, (iii) Irregularities and (iv) Barriers.

\section{Theme 1: Mobility}

OSs face experiences in terms of mobility impediments. They face impediments on mobility in terms of feelings and affections, changes, irregularities and barriers. The sub-theme on feelings and affections (coded 432 times and always happens) base from paralyzing whereas the sub-theme on changes (coded 456 times and always happens) base from improving English language skills, better study conditions, acquiring specialist knowledge and career opportunities. Similarly, the sub-theme on irregularities (coded 389 times and often happens) base from non-equipped houses/flats to hire and the sub-theme on barriers (coded 546 times and often happens) base from transportation and expensive tickets to fly home regularly.

Overseas students agree that they feel that they feel paralyzed upon arriving North Cyprus. Most of the participants say that it was their first leave of their homes due to their studies in NC. Others admit that although they are studying in $\mathrm{NC}$ through years, they feel paralyzed because NC is not their own country. They do not feel that they belong to the country. Some qualitative data from OS students regarding feelings and affections sub-theme on mobility theme were given below. Hence OS34 said that:

...this is my second year here. Last year, I was crying all the time. I was feeling paralyzed and very bad. Now, I am ok. I need to graduate, so I study hard to come to the end. It is not easy for us.... I am from Zimbabwe. My family wanted to visit me, but tickets were very expensive. They could not afford it. I learn to go shopping, meet my needs, apply to a hospital... I was not doing most of these things alone at home, or was doing these things with my family. It is not same here. I am surviving; I am doing my best.

Similarly, OS5 admitted that:

When I first arrived on the island, I really felt loneliness. I felt that I am isolated from my family. I am still homesick. Now I am in my second year here. I am accustomed to the island and its living conditions, but people here mostly make me feel that I am a foreigner here.

On other hand, OS6 believed that:

This is my initial year of my graduate study. I graduated from a university abroad and got acceptance to the graduate study in a university in NC. After the European university I graduated, I felt really paralyzed seeing the university and the city. I am shocked in terms of the options we are offered while applying, the building we are shown on internet, the block of living places we are offered to live, all shocking points for me. Because what I am offered and what I find are not at the same quality. In a way, they deceive us in terms of the conditions they offer. 
Overseas students reveal that their most common reason for having mobility based changes constitute the reason that they would find better opportunities to improve their English language skills, benefit from better study conditions and acquire their specialist knowledge. Improved language skills on English have been considered a fundamental part of conducting research and improving the quality of learning process for acquiring specialist knowledge. Their career opportunities are improved when they develop their language skills, and get benefitted from the better study conditions and acquire specialist knowledge. Some qualitative data regarding the issue are presented below. Hence, OS1 agreed that:

Many things have changed in my life as soon as I arrived to the island. I study in an English medium university and department. The only thing I face as an impediment is that lecturers mostly use their native language in the lessons. This is a real impediment to improve my English language skill. I need to use English to improve myself in my field of study, acquire specialist knowledge in my field and catch career opportunities. When, I observe the previous graduates from my department, I see that neither their English level is not as advanced as competing to the world graduates nor their specialist knowledge. This is a very important barrier in front of us. Because I believe our career opportunities are very high. But we are not raised in that quality.

Similarly, OS21 admitted that:

I am from Turkey, I studied in an Anatolian High School but my English is not good enough to follow the English medium department I got acceptance. Most of the courses are in Turkish. Lecturers, assistants do not use English language while they conduct the classes. This is in a way, ... they deceive us with the level of the quality of the lessons offered. I was dreaming of catching the highest level of English actually.... I also feel that I do not acquire specialist knowledge in the class, I am not offered the highest quality. I observe the level of quality offered to me in my studies and the level of quality my twin brother has in the same department in a most popular university in Turkey. We graduated from the same Anatolian high school. Our educational background was similar before we went to the university. Unfortunately, our level of English and our level of specialized knowledge offered are not at the same quality. When the time comes and we graduate, I do not think that I will have the highest level of opportunity in terms of career when compared to my twin brother's career opportunities.

OS4 thought that: I need to improve my English very much.
Otherwise, I cannot survive in the working world. I am planning to work in Canada as soon as I graduate. Graduates should have improved English skills, because English is an international language. Most of the international companies ask for an international diplomas and a document showing the level of English at the international level. I study prep school since my English was not proper to continue with the department. I needed to improve myself apart from the prep school. They were not enough in teaching English at the international level. Before I entered the prep school, my IELTS overall result was 4.5. Upon graduating from the prep school at intermediate level, I sat for another IELTS exam. The overall result was 5 . You see, they are missing something in teaching English. They should teach at the international level. The level and educational background of the students are important for identifying the level of the class. Then, it is the quality of the program and the quality of the teachers makes sense. Motivational level of the student also makes sense. I sat for IELTS again when I had a summer program in Exeter for 3 months and I got overall 6,5 . It was awful. The program I carried out there was at the intermediate level. The teachers were very motivational and qualified. They all had $\mathrm{Ph} . \mathrm{D}$. on teaching English and had over 15 years of teaching English. It was the important point I think. Here in NC, I did not have an English teacher holding a Ph.D. and having experience for more than 15 years. They were all newly graduated teachers unfortunately. We were like trial boards for them. Since they gain experience, they change their work place. They do not stay at there. There is an important point here I think. They are not satisfied with the conditions where they work. As soon as they find another job opportunity, they change their work place. Unfortunately, prep schools cannot offer a qualified program, qualified and experienced teachers and satisfied working conditions for teachers in $\mathrm{NC}$.

Hence, OS12 said that:

At the departments, the quality of the teaching staff is not high. Most of them completed their BA, masters and PhDs from the same university and are employed from the same university. I believe, supplying competitive atmosphere require teaching staff to study and/or work at various atmosphere and various universities. Each atmosphere contributes to the teaching staff's personality, academics and/or maturity.

Nearly all of the participants believe that they are unable to find well-equipped houses/flats to hire as an overseas student. There are sharing and/or private dormitories for 
them to hire, however they need to hire a house/flat, what they find is empty and/or older houses/flats to hire. Most of the houses/flats they hire do not contain relevant heating and/or cooling systems. Additionally, participants living at private dormitories agree that owners of the private dormitories mostly do not offer good food and/or some dormitories do not even serve food. Therefore, they need to eat outside most of the time. Eating out costs too much for a student and is not always healthy. Similarly, there are any unique rules and regularities established which give rise to OSs behaves however they want. Some qualitative data regarding the impediment are given as follows. OS45 said that:

... At first I hired a shared dormitory. There were regular electricity cuts in the dormitory. I hired a flat to live. The flat had nothing. I needed to buy everything from top to bottom. The landlord did not put anything in the flat... no furniture, no refrigerator, no kitchen ware... nothing. I bought everything. I have been living in the same flat for several years, I am happy with the location of the flat. But the landlord asks for increasing amount of rent. I have been paying with pounds, and the landlord asks $10 \%$ increase in the rent every year. Pound increases itself and landlord asks for $10 \%$ increase. Being a landlord in NC is very profitable.

Similarly, OS2 revealed that:

I was living at the ground floor of an apartment last year. It was designed as a flat, but it really was a store. I was giving a lot of money to the owner. This year, I am at a private dormitory. I live alone in my room. There is not any place for me to cook my meal. The dormitory also does not offer food. I need to eat outside. This is not good for my health and they sell expensive food at restaurants. I was buying home-made food from a supermarket. Eight of my friends got poisoned from the meals of that supermarket. I no longer buy anything from that supermarket. I want to have a kitchen to cook in the dormitory and/or places offering healthy and fresh home-made food.

Additionally, OS19 agreed that:

I was living at a flat with my four friends two years ago. I had to pay lots of money. It was really expensive to hire a house and/or a flat in NC. I needed to cook myself, pay my bills, welcome friends of my flat-mates nearly every day and/or survive as a student. I changed my place. I live at the university dormitory since then. I am happy there. They offer food in the morning and in the evening. They do not offer good food. I mostly do not like their food. I need to buy my lunch every day and mostly buy my dinner. Additionally, dormitories are also expensive depending on the number of friends living at the same room. They are also crowded. I have a roommate. I do not need to pay my bills. I do not need to cook. But, students sometimes shout, fight while I am studying. They make much noise, which disturbs me a lot, but the managers ignore such kind of things. There is not any kind of regulation.

Hence, OS9 revealed that:

Dormitory owners do not declare any kind of rules for the students staying at dormitories. They just take their money when time comes. Some students bring their girlfriends to the boy's dormitory; they spend hours and hours alone in their room locked. Some students take alcohol outside and/or inside the dormitory. They shout and fight with others. We do not have a door-closing time. I observe most students come very late to the dormitory with their girlfriends who are all drunk and go into their rooms. No one controls such kind of irregularities.

Nearly all of the participants agree that they need to wait hours and hours for buses of the university to arrive on the campus because there is not any established transportation system in NC. This makes them wait and wait for hours. More than half of the participants agree that the bus line has been mostly changed without announcing it to the students. Therefore, they may not be able to reach their studies in time. In addition to this, overseas students feel that tickets to and from $\mathrm{NC}$ are very expensive. They are unable to buy tickets whenever they desire. Most of them live on shared places; therefore their families cannot be able to visit them regularly. Some qualitative data regarding the barrier on transportation and expensive tickets to fly home are presented below.

OS3 revealed that:

My university does not provide regular bus services to the city center. I need to walk for a long way to reach the bus stop. The times of the buses are not regular. I may need to wait hours and hours for the bus to come. When it is rainy, or very sunny, nearly all of the bus stops do not have shelters. While waiting for the bus to come, I have been always getting wet under the rain or getting negro under the sun.

Additionally, OS23 admitted that:

In my first year in NC, my family from China wanted to come here; they paid a fortune to the plane tickets and to the hotel for accommodation. It was an amazing experience. I felt very happy when they visited me.... NC is a very expensive country.

Hence, OS22 believed that:

I cannot walk to reach my lesson when I miss the school bus because there is not any walking line for the pedestrians. Vehicles are very fast at the main road. The buses are mostly irregular in their lines. I wait in the line they announce, but the bus does not 
appear on that line. This happens nearly at all lines. I have complained about the issue for several times. It is ridiculous that nothing has changed. When I have a class at 9:00 am, I need to take the 8:00 am bus. When the bus does not come, I miss my class unfortunately.

\section{Theme 2: Adaptation}

OSs experience adaptation impediments in terms of feelings and affections, changes, irregularities and barriers. The sub-theme on feelings and affections (coded 412 times and often happens) base from emotional distress and change in personal affection state whereas the sub-theme on changes (coded 443 times and always happens) base from language, culture, religious; student health insurance; and health system. The sub-theme on irregularities (coded 390 times and often happens) base from sleeping disorders; unhealthy-environment and attendance problems. Similarly, the sub-theme on barriers (coded 321 times and usually happens) based from contacting with local students; financing their studies and unhealthy environment.

More than half of the overseas students reveal that they feel alienated emotionally and they believe that they change in personal affection. They agreed that upon arriving $\mathrm{NC}$, they were feeling helpless at first and had a feeling that they could not be able to manage their lives as a university student. They need to survive in NC, such as they need to supply their food, establish a healthy environment, pay their bills, supply their accommodation and/or transportation as well as establish their network. However, they feel relaxed, overcome their fears, trust themselves through time and take more responsibility of their lives, which changes them personally. Some qualitative data regarding feelings and affections on adaptation dimension are presented below. Hence, OS27 admitted that:

I could not adapt myself when I first arrived in NC. I could not adapt to environmental conditions, house tasks to do like paying bills, cooking, etc. I could not make friends around and I could not make local friends, because I needed to make new friends in my new school and new class. It was a huge deal at first. Environment is not as clean as I expect to see. Also, I need to pay my bills, buy my food and/or cook for myself, walk home or wait buses for hours.... I suffered a lot from these issues a lot. I felt really bad at first, but through time, I felt that I am a mature person. I need to do all of these things. Now, I have adapted to the environment, my school, my university, the concept of 'being abroad', tasks to do, have made lots of friends... I feel that all these things have made me change my personality. I think, adaptation is closely related to the maturation. My emotional distress fades through time, and I have adapted myself (OS27).

Upon arriving to the host country, the participants felt language, cultural and religious based changes in their lives. They also suffer from health insurance. At first they feel excited to immense themselves in the new language, culture and religious based changes, however they suffer from communication in the new language, new culture and new religion. Overseas students from Turkey mostly do not suffer from language and religion based changes, but overseas students from other countries suffer from these changes very much. Turkish students agree that they may not be surviving with the accent the Turkish Cypriots have. However, students from other countries reveal that they have limited places to pray, they are unable to understand and comprehend Turkish very well. Both Turkish students and students from other countries feel culture shock for some time. Besides this, more than half of the students with foreign languages cannot explain themselves especially when they apply to the hospitals. They complain that most of the doctors cannot understand the reason why they apply to the hospital. More than half of the overseas students emphasized that the doctors, especially at the state hospitals in NC refuse to touch on the foreigners to see what they suffer from when it is needed. Similarly, more than half of the overseas students believe that they do not smell and live a healthy environment. Some qualitative data regarding language, culture, religious and health issues on adaptation dimension are given below. OS14 admitted that:

I am Christian. When I first arrived to the island, I had nowhere to rite. Time has passed and we have a place to rite. This is nice. Muslim people go to the mosques and we have a place to go. We have religious and language and cultural based differences with the Turkish Cypriot society.

Similarly, OS6 agreed that:

I am from Turkey. I do not have language-based problems in NC, but I may not understand the accent of Turkish Cypriots. We have some cultural differences with NC people. I am very hospitable when compared to my Turkish Cypriot friends. We are in a way different.

In addition to this, OS49 emphasized that:

My health insurance abroad and the health insurance in $\mathrm{NC}$ are quite different. In $\mathrm{NC}$, as university students, we aren't offered any health insurance. I may get some discounts from the hospital I apply for, but I am not being served without any money unfortunately.... When I apply to the state hospitals, the doctors do not even touch on me. I think they do not like foreigners in NC. They ask what I am complaining from, with my English, I try to explain it. But, most of the time, I realize they do not even listen to me. I do not know even whether they understand my English or 
whether they know English. I do not know Turkish, then what to do? We need to overcome the language difficulty at the hospitals and with the doctors. I do not have to learn Turkish to get well soon. Once, we went to a state hospital. The doctor did not understand what happened to my friend. He fainted after a while waiting in the emergency room. The doctor called another doctor who can understand English well. Then my friend was cured. He got fainted due to the very higher fewer he had. The doctor did not touch on or cure him to understand this. We were asked to pay some money even at the state hospitals. State hospitals in the world in general do not ask for money when you have a student ID card. In NC, we need to pay for everything, bits and pieces.

Most of the overseas students agree that they need to work for overcoming financial difficulties they have. Some of them are scholarship students, whom also require to work. Most of the students working in some places after lecture times may have some sleeping disorders. Most of them feel that they have attendance problems due to the unattained working conditions in NC. Additionally, most of the overseas students believe that cleaning the environment is not managed very well. They complain about the environmental problems they face. They smell and see garbage in front of their living places. They believe that they are not offered a healthy environment. Besides this, overseas students need to contact with local students and local society. Local students and local community mostly feel alienated from the overseas students. Nearly all of the participants agree that whenever they need to contact with locals, they feel shock at first. Through time, they establish their network, but locals mostly refuse to be in this network. Some qualitative data from the OSs regarding barriers on adaptation dimension are presented below. Thus, OS30 thought that:

The municipality here generally does not collect garbage on time. Some kind of smell of food surplus attracts cats and dogs in the street and they attack the garbage. The uncollected garbage means torn garbage scattered all over the street till the municipality's garbage truck comes. It smells really bad for all day, all night. This is really bad for our health. We smell bad garbage and mosquitoes bite us. We live in an unhealthy environment.

On the other hand, OS31 admitted that:

I read daily local newspapers in NC. I see news on the food containing drug residue. Local people suffer from the increasing cancer cases throughout the country. I wonder whether there is a positive relationship between the food containing drug residue, which is easy to buy everywhere, and the increasing cancer cases throughout the country. I have not seen or heard any kind of research carried out on this topic especially, but I believe there is a positive relationship between them. This means that the producers of fresh vegetables and fruits should be inspected very closely and the drugs causing residues should be sold under close governance. As far as I understand, producers can buy and use these drugs easily. It is not their concern because I believe they produce for themselves and their families as well as for the others.

Hence, OS47 agreed that:

I am a scholarship student, but I need to work because I am married with a child. My wife is a student, too. Our child goes to day-care. I work in a café during the day and a restaurant at night. We close at 3 am every morning. I go home very late. I do not earn much, but I need to work to support my family and myself. I should not lose my scholarship so I study hard. The university I am enrolling does not ask for full participation to the lessons. Teaching staff does not take attendance. It is good for me.

Similarly, OS12 discussed that:

I feel difficulty in contacting the local students. I think that they do not like my colour and my clothing style. It is not only me feeling like that. It is same at school environment and out of school environment. I observe local students and tell 'hi' to them. They just say 'hi', but we never go beyond that. I usually put on some long clothes I put on in my country. This is my traditional clothing style. I also wear some casual clothes, like jeans. But I enjoy my traditional clothes. When I see the local friends especially, they do not like to even say ' $\mathrm{hi}$ ' to me. As I said before, it is not only me. There are other overseas students I know feeling like that. This is an impediment for me, because I have local friends in my class. I need to contact them regarding my lessons, share some resources etc. They mostly refuse to share anything with me.

Thus, OS10 agreed that:

One of the most important impediments I face is related to finance issue. My family cannot send money for my studies. Actually, what they send me is not enough to support myself. I need to finance my studies and my living. I work to solve my financing issue. The condition in my work-place is not superb. I work till $12 \mathrm{am}$. I go home and sleep. If I have a class early in the morning, I generally miss it because I am sleepy. Most of my classmates work in different places. When the term starts, we ask the teaching staff to arrange classes depending on our working schedules. There are only 12 
students in the class. It is generally ok, they arrange the classes according our working schedules. It sometimes may not happen due to clashes. I failed due to the clashes last term. I got NG (non-grade due to attendance problem) from that lesson. I need to finance the lesson again.

\section{Theme 3: Internalization}

OSs have internalization impediments in terms of feelings and affections, changes, irregularities and barriers. The sub-theme on feelings and affections (coded 311 times and often happens) based from acceptance process and integration process whereas the sub-theme on changes (coded 538 times and always happens) base from institutional and curricular standards. Similarly, the sub-theme on irregularities (coded 389 times and often happens) base from shaping the world wide knowledge based society and promoting scientific exchanges. The sub-theme on barriers (coded 419 times and often happens) based from increased population of overseas students.

Nearly all of the participants agree that they face acceptance and integration process till they establish their academic network. While establishing their network, most of the participants believe that the acceptance and integration process take place in a difficult way for them. Some qualitative data from the OSs regarding feelings and affections on internalization dimension are presented below. Thus, OS32 admitted that:

This is my first year. I feel frustrated even anger when I face difficulty in doing basic tasks such as going to shopping, and/or navigating transportation. I sometimes think that I am stupid. I have feeling of 'stupidity' because language is a barrier preventing me having effective communication with the local people. I cannot chat with my neighbors around, we cannot go further from 'hi, how are you?'. I feel as if I am incomplete.

Similarly, OS29 revealed that:

I have sleeping disruption due to the barriers I face in NC. I have language as a barrier, cultural differences are also barriers, and also I have religion as a barrier. These barriers are barriers I need to overcome. Local people do not like overseas students much. They do not welcome overseas students very much. I have a smiling face towards local people, but they do not even say 'hello' to me. I experienced depression last year. I still use some pills for overcoming the depression. I grow up in a society where people node each other, say 'hello' etc. Here it is not same. I have a completely different environment in NC.

Similarly, more than half of the participants reveal that they experience changes basing upon institution and curriculum. Most of the overseas students have obeyed various standards regarding institution and curriculum before they get acceptance from a university in NC. Their difficulty regarding the issue is on the quality of the institutions, teaching staff, the curriculum and research based activities as well as level of internalization of the quality issue. Some qualitative data regarding changes on internalization theme are presented below. Hence, OS49 admitted that:

I was studying in an American based curriculum for my undergraduate. After I graduate, I won a scholarship to a university here for MBA degree. The curriculum here British based. I have changes regarding institution and curricular based. The qualities of both institutions are not similar, unfortunately. I do not hear pure English spoken by the teaching staff. This is ridiculous because the program is English medium, which is against institutional integrity. Teaching, learning and research should have particular sets of goals embodied in the degree of program of the university and the specific curriculum followed in the department I follow. However, the MBA program I follow in NC does not embrace all those activities and experiences provided the school to enable us to achieve the intended goals, which is against the curricular standards. I work in a business here in $\mathrm{NC}$ in order to reach my aim. However, what we do in business is not parallel what we study. I believe learning should reflect the objective of the curriculum and should support the working world; I mean learning and working should support each other.

On the other hand, nearly all of the participants believe that they face irregularities on shaping the world-wide knowledge based society and promoting scientific exchanges. Some qualitative data regarding irregularities on internalization dimension are given below. Thus, OS50 said that:

I am a postgraduate student. I need to write articles. My knowledge regarding my field should shape the world and promote scientific exchanges. I applied to scholarship to an exchanging program on my field in the United Kingdom. I was refused due to the level of articles I have produced so far. The professors there expect us to write and publish in the most distinguished journals, where we mostly get refuse. What I produce is the indicator how I am raised in NC. I graduated from NC universities so far. It is not only me getting refusal from the most popular universities in my field, I have got some friends like this.

Similarly, OS38 admitted that:

As postgraduate students, we need to come together with our colleagues all over the world. Our knowledge of the field shapes our future. We 
need to promote scientific exchanges. This is not like that with the graduates from NC universities in general. After I graduate, I will be one of teaching staff of my university, but other universities in NC even won't accept me with my degree. Unfortunately, this is what we face after graduation. If someone looks at the background of the teaching staff of each university in $\mathrm{NC}$, he or she will see that the teaching staff is the graduates of the same university. I think there is something we miss here. Universities need to be open to the teaching staff from all over the world. They should be at advanced level that internationally recognized teaching staffs prefer to teach at universities in NC. This is necessary for promoting scientific knowledge, exchanges and getting improvements throughout the world. We should not play hide and seek. Universities in $\mathrm{NC}$ should be at the international level, but most of them are not at that level yet.

Also, nearly all of the participants say they face barriers basing upon the increased population of overseas students. Some qualitative data regarding barriers on internalization dimension are presented below. OS42 revealed that:

Local people generally do not prefer to contact with the students from other countries. This is not the reason that they do not like to contact, but there is an increased population of students from all over the world. There are nearly 15 private universities of which at least 5 of them have more than 10,000 students. There must be nearly 100,000 students in NC, I guess, which means nearly $1 / 3$ of the population of NC. It is not easy to handle and plan educational, societal, cultural, traffic-based, student-based issues for such a big population. Each university tries its best to deal with these issues alone, but when it is governmental based decisions, they stuck. Governmental people, such as the Minister of Education, need to take some effective decisions for solving issues. But, government does not have such kind of mission as far as I observe. They have an institution for supervising to the higher education in $\mathrm{NC}$, but it is not as active as it should be.

\section{Theme 4: Maturation}

OSs experience maturation impediments in terms of feelings and affections, changes, irregularities and barriers. The sub-theme on feelings and affections (coded 359 times and usually happens) based from social development whereas the sub-theme on changes (coded 391 times and sometimes happen) based from academic autonomy. Similarly, the sub-theme on irregularities (coded 402 times and usually happens) base from insufficient fundamental social conditions whereas the sub-theme on barriers (coded 410 times and sometimes happens) base from employment conditions.

More than half of the participants reveals that they feel barriers on social development. They believe that they want to make international friends especially for improving their oral skills in a foreign language. Some qualitative data regarding the issue are presented below. OS17 admitted that:

I am an overseas student in NC. I am trying my best to develop socially. Local students, students from other countries mostly contact with the people and/or students from their society. There are international students in NC. It is a place where we can make international friends. I have got some international friends, not many. We go out together, meet people from other cultures, but we just say 'hello' to each other when we meet. We generally do not interfere each other.

Similarly, OS35 agreed that:

As soon as I arrived in $\mathrm{NC}$ three years ago, I made some international friends. Through time, I realized that our interests, priorities are different. Now, when we meet in a café, we just say 'hi' to each other. That's it. Interests, priorities, and so on actually impede our social development. I realized that it is similar with other friend groups. Each group has students from one culture or society. I am with my network and they are with their network. We do not interfere each other. However, there are lots of overseas students studying in NC universities, and I believe it is a big chance to develop socially and internationally, but it is not like that (OS35).

Additionally, nearly all of the participants feel changes basing upon academic autonomy. Some qualitative regarding academic autonomy on maturation theme are presented. OS44 agreed that:

Academic autonomy has close relationship to be free in producing science. It does not mean that I am free to do what I want, but everything should be in the regulations of science and the university as well. A university's regulations cannot be reversed with science. They should all complete each other. As a postgraduate student, I write articles. I make research by myself, write the paper, but when it is time to publish, my supervisor asks me to write his/or her name. This is a big problem throughout the universities in NC. Otherwise, we cannot graduate. I had a friend, refusing to write her supervisor's name to the article, the supervisor refused to continue with her. He could not even find another supervisor for herself. Then, with the help of the dean, she could be able graduate. I question the duties of my supervisor. They, I mean the supervisors, earn money for doing supervision 
as a duty. But, they do not. I am not satisfied with my supervisor. Most of my friends don't either. They and I believe that it is only in NC we face such kind of issue. I can clearly say that my supervisor never helps me in my thesis, in my academic writings. To be able to graduate, I need to write the name of supervisor into the academic paper I write. This is not fair. I had a scholarship to a university in England for 12 months, I wrote an academic paper with the research I had there. My supervisor in that university wrote the introduction and methodology sections of the paper. I analyzed the data, wrote about the findings and discussed them. When we finalized the paper, we published it together. This is academically ethical. But, what supervisors do in $\mathrm{NC}$ is not ethical generally and it is against the academic autonomy.

Similarly, OS8 believed that:

When teaching staff gives us a presentation topic, it is what we learn in detail. Distribution of presentation topics means autonomous learning here. We have opportunities to learn about the other topics, but we do not. This is because the teaching staff does not evaluate our understanding of each topic. Preparing and presenting a presentation topic as if mean each student in the class has learnt about each topic. It is not like that. I know it is the responsibility of the student to learn about each topic, but presentations are not at that level and the teaching staff needs to check the understanding each topic. He or she should not stop when the presentation of the topic has finished, but keep going to check everybody's understanding. I know I need to learn autonomously, it is my responsibility to learn it, but the teaching staff should make sure that everybody has learnt each topic and has completed his/her responsibility of learning.

Similarly, nearly all of the participants agree that they face irregularities basing upon insufficient fundamental social conditions. Some qualitative data regarding irregularities on maturation dimension is given below. OS26 said that:

I feel anger when I see insufficient social conditions such as the conditions we should have while learning in the class. We do not have projectors for example. I do not have to listen to the teaching staff all the time with great attention. I do not have to beg for a projector from the department when I have a presentation. I do not need to hire a projector for big prices. I do not have to wait hours of hours at my teaching staff's door. I generally cannot find the part-time staff in their offices although it is their office time. I sometimes cannot reach the full-time staff when it is their office hour.
Facilities, office hours etc. are our fundamental needs. But we are lack of them. Such kind of things de-motivates me. If the university owners in $\mathrm{NC}$ want to survive at the international arena, they should maintain their social conditions within the system the international universities globally have. Otherwise, they are kept apart from the international level. This means that as students of these universities, we are also kept apart from the international level. Being an international requires being in a system. Managing an internationally recognized university requires having a model through identifying the students' needs, interests in terms of the institution and in terms of the university industry. There should be globally internalized standards in order not to be insufficient for the best practices and there should be guidelines leading globally the best service quality.

Additionally, OS1 revealed that:

I observe many overseas students who are married with a child or some children. They are students. I wonder how they earn their money, and how they handle the living conditions. It should not be easy. Social conditions such as overcoming social relationships, getting acceptance from the local people and local students, working conditions and studying conditions are not easy to handle, I think. I wonder how they feed their children and pay educational needs of their children? (OS1).

More than half of the participants face barriers on employment conditions. The participants reveal that they may need to work after class hours, but the conditions offered to them are not satisfied. The issue they complain is that they may work as an assistant at the university, and/or as a part-time at a place. However, work conditions are not at the level as it should be. Some qualitative data regarding the employment conditions on maturation dimension are presented below. Hence, OS40 believed that:

I am a student assistant at the library of my university. I study undergraduate program. My working hours are arranged due to my program. It sometimes happens that I am called when I am not working or when I am in the lesson. I work for about 20 hours per week. I am not given a sufficient amount of money. I need to work, I could not find a place to work and earn much money.

Additionally, OS16 revealed that:

I am a teaching assistant in the department of the university where I am a postgraduate student. I teach 8 hours, have 6 hours of lesson timing. I am required not to do the teaching staff's photocopying jobs, but I am asked to do. My work schedule covers photocopying issue, but just the chair's issues. I sometimes feel that I am below the 
departmental secretary. I worked with different departmental secretaries in my department. They show the similar patterns in terms of the work schedule of the teaching assistants. They do not want to do the photocopying issues, they ask me. However, it is their duty to help the teaching staff when they do not have sufficient time to do it. I am sometimes asked for help from the teaching staff. However, the chair always asks them to do their photocopying issues by themselves, not asking the teaching assistants, but they do not behave in that way. I am supposed to work 15 hours, because I am still a postgraduate student. The reality we face is not like that. I once refused to do a personal job of a teaching staff, the chair called me to warn. I told the chair that it was not my duty to do the personal duties of the teaching staff; the chair told me that it is ok. I think the teaching staff lied about me while complaining.

Hence, OS33 said that:

I am a married overseas woman. I need to work to earn my family's living. I will give birth 6 months later. My husband also works. I work as a sales person in a clothing shop. I am happy there. It is a tiring job, but I need to work, so I bear the conditions. I sometimes cannot follow my lessons. I generally cannot attend my classes because of the work conditions and due to my pregnancy. It is similar with my husband. We talked to the teaching staff. They told us that we should sit for the exams only. This is good for us, but I think there is something wrong with this. I come to NC to study but I am not obliged to attend the lessons, I do not have any attendance problem. I can work with my student ID card. No one asks me whether I am legal here or not. The job owner just wants me to work. I pay my money to the university accountant, and I am free here. I don't know whether it will have good results in the future.

\section{Conclusions and Discussion: Managing Changes for Proposing the Managerial Model}

Lifelong learning and institutional development have positive relationships. Hence, it requires human and societal development to promote opportunities (Billett, 2010). Lifelong education appears to be continuous. Being an overseas student in a foreign country is part of the lifelong education. Adaptation process for overseas students appears from the very beginning upon arriving to the host country. Having an increasing level of success at adaptation process gives rise to continuous success at school and professional school life. Hence, the more level of adaptation of overseas students to the new culture and the society, the more level of success they have. Intercultural adaptation is an intercultural learning, facilitating understanding the learning experience, having self-knowledge, being aware of the others and having values and global view (Gill, 2007). A study conducted in Cyprus on international students' intercultural experiences identifies impediments on interactional barriers, affectionate, strategies to survive and strategies to improve (Georgiou and Savvidou, 2014). Similarly, language and study problems are the identified two difficulties faced by overseas students in the Australian context (Samuelowicz, 1987). In addition to this, it is found that international students in the American context face higher levels of discrimination and homesickness than the domestic students. The higher level of discrimination they are exposed to, the higher level of homesickness they feel (Poyrazli and Lopez, 2007). Feelings of depression, anxiety and withdrawn as well as finding hard to focus to the topics are the reported symptoms of homesickness. Intense homesickness, the most problematic case, can give rise to disorders on mood and anxiety, mental and physical health problems which may increase cases of withdrawal from the school (Thurber and Walton, 2012). Stress related diseases among the international students are higher than the domestic students (Ebbin and Blankenship, 1986). Thus, student mobility to an unfamiliar context leads to pedagogical adaptation and culture shock, which affectively, behaviorally and cognitively affects students in the unfamiliar context (Zhou, Jindal-Snape, Topping and Todman, 2008). Additionally, international students' maturation, individual development and their intercultural adaptation to different environment, educational context, culture and society are considered complex which affect the nature, development and change of students through time (Gu, Schweisfurth and Day, 2010). On the other hand, another American based study reveals that frequencies of overseas students suffering from stress related diagnoses are higher than domestic students and they also suffer from language based difficulties, different beliefs on health, lack of knowledge and stress at the acceptance process (Ebbin and Blakenship, 1988). Overseas students should have grown up, be mature enough, develop themselves as well as adapt recent context and/or changes they face through time. Analysis of the current study reveals impediments on maturation, internalization, adaptation and mobility in relation to feelings and affection, changes, irregularities and barriers.

Having difficulty in comprehending the local language, tuition fee and affections felt due to isolation are identified in an Australian context where international students face throughout their academic lives (Robertson, Line, Jones and Thomas, 2000). Globalization of higher education should be discussed deeply by the scholars and education managers (Obeng-Odoom, 2012). Learning and growing in an overseas context brings complexities with it. Such kind of transitional experiences as well as intercultural adaptation affect the natural change of the overseas 
students and contribute a lot to their change process as well as development through time. They are mostly affected by complex set of focuses regarding having mastery in language, interacting socially, developing personally and having academic outcomes. Such kind of focus points has contributed to the management of intercultural adaptation and re-establishment of identity in the new context. Similarly, student adaptation, identity change and student success have a positive relationship with the personal, pedagogical and psychological factors as well as organizational culture and social culture. Therefore, overseas students' development, change and success have positive relationship with the degree of support given and with the degree of contact with the local environment $(\mathrm{Gu}$, Schweisfurth and Day, 2010). Such kind of deep discussion leads to a managerial model to establish and such kind of proposed model is based on managing accommodation, transportation and safety; managing studentship; managing students' health; managing students' welfare and managing being worldwide.

The proposed managerial model on managing accommodation, transportation and safety: Initially, the proposed managerial model has been suggested to include managing accommodation and transportation on behalf of students. There is not an established transportation system in NC. Accommodation is an impediment for international students and may decrease the quality of higher education (Obeng-Odoom, 2012). Similarly, physical facilities, Internet and phone are channels for servicing (Sousa, Amorim, Pinto and Magalhães, 2016). Students are all customers for a business and they deserve the best quality in getting service. In a research conducted in an Australian context, it is found that international students in the university accommodation feel security physically and feel less threat to their social security. Therefore, university accommodations are suggested to improve by the governments and by the universities (Paltridge, Mayson and Schapper, 2010). University students in NC require not suffering from this since universities ask for some amount of money to transportation, but they do not offer regular buses and/or offer irregular service in terms of transportation. Similarly, student safety is another issue to be considered since student safety is a systematic problem especially in overseas contexts. Overseas students abroad constitute an international student industry and it has a big share. It is sometimes impossible to convince the higher education providers as well as educational planners to discuss the international student-safety frankly (Nyland, Mewett and Marginson, 2010). Higher education providers are required to examine the reason/s of irregularities and take the necessary steps to solve the problems in terms of transportation, accommodation and student-safety since these issues are the basic needs the overseas students require upon the new context. The more level of success the higher education providers as well as educational planners get from transportation, accommodation and safety issues, the more level of student satisfaction and success they will see. The level of being prepared to such kind of matters means to have the highest quality of life and joy of life of the students. Since homesickness is an important problem to solve for overseas students, depression, anxiety, withdrawn behavior, as well as difficulty in focusing the main points are worse for the students being healthy, satisfied as well as having a fruitful educational life (Thurber and Walton, 2012). Educational planners should not ignore student accommodation issue since all of the dormitories and/or houses/flats should have the similar kind of offers and quality offered to the students. Students pay well to the dormitories but they still face impediments in terms of Internet usage, health issues, regulation based issues and/or food issues. All of the dormitories need to be hired for the name of the universities, and they should serve similar qualities to each student.

The proposed managerial model on managing studentship: Most of the participants agree that there are many overseas registering to the universities work effectively, but they do not study. They just earn money. Overseas students in $\mathrm{NC}$ are either undergraduate or graduate students. Most of them are highly donated with foreign language skills and/or experienced in their field of study/work, which are relevant and appealing points for most of the work owners. Such kind of overseas students are skilled migrates for the NC. Additionally, international work experience has contributed to the work place to be able compete globally. Such kind of appealing and relevant points give rise to the country to reposition its place in the world economy (Gribble and Blackmore, 2012). However, Turkey has managed economy of NC. There is not any kind of competition brought among the companies in NC. Most of the work-place-owners only need to earn their money in a way. Most of them do not consider rights of the overseas students even the students are highly skilled since they know about the struggles the overseas students face in NC. Therefore, politicians at the government should be aware of the fact that most of the overseas students who require work to earn their living in $\mathrm{NC}$ are qualified enough to earn much money, but the work-place owners do not pay them well since there is not any kind of competition exist among companies throughout the country. Work-place conditions for the overseas students are not as it should be. On the other hand, overseas students are required to accept poor working conditions, but numbers of overseas students accepting such kind of poor employment conditions are very high (Nyland, Mewett, Marginson, Ramia, Sawir and Smith, 2009). Students who would like to work part time, they should be able to work under some conditions and participate in their studies regularly. Thus, they should be able to work part-time under their student visa. They should pay their tax to gain student visa. Their irregular working conditions and irregularity in work-force facilitates work owners gain unfair profits and earn a lot from cheap labor. Students do not earn much money, but 
work place owners do not pay taxes for overseas. Therefore, local workers cannot find job in the areas overseas students work. Higher education providers and governmental authorities planning education are required to provide official and regular rules arranging overseas students' working conditions. Such kind of rules should regulate overseas students' working conditions in a way that they attend their classes regularly and work part-time under some regulations. Those who are non-attendant to the classes regularly should be reported by the university authorities for making deep search about the issue and, if necessary for deporting purposes. Those who would like to earn money should work under some circumstances and limited hours. Unless the student does not attend to the summer term at school and if the student desire to work full-time, summer term can be an exempt. International students become immigrants of a country since they develop the country's economy due to the highly skills they have. Such kind of strategy has influence on shaping migration and policies adapted for international students. Australia and Malaysia are two examples having both brain drain and brain gain, which have obtained various strategies to international student migration in order to increase the number of skilled migrants and to sustain economic development (Ziguras and Law, 2006). Therefore, governmental policies are required to establish a work permit system and to establish an entry recording system. Those who would like work part-time during the school time and full-time during the summer holidays should have a work permit from the governmental authorities to be stamped by the owners of each work place. Similarly, those entering NC should be registered to the entry recording system and should submit the record of their entry to the university while registering. Such kind of system requires governmental authorities, safety authorities and providers of higher education to cooperate essentially.

The proposed managerial model on managing students' health: Overseas see health conditions as an impediment in NC. They believe that they suffer from emotional as well as stress based problems. Such kind of problems significantly affect negative their well-being and academic performances. A well and purposeful support by the advisors also decreases the amount of emotional and stress related problems with the overseas students and decrease the amount spent at the counseling services (Hyun, Quinn, Madon and Lustig, 2007). Stress itself influences health and illnesses due to the changes and discontinuities overseas students experience in their lives (Dearmond, 1988). Higher education providers are requested to manage their counseling services and advisory services successfully. A purposeful advisory system will decrease the amount of questions and problems the overseas students have. Similarly, a well-planned counseling service within each university will decrease the number of students feeling emotional and stress related problems. Therefore, overseas students will feel relaxed because they will get immediate response to their questions. The overseas students also agree that environment is not clean since garbage is not collected regularly; there is air pollution, which smells really bad from time to time; there is drug residue on the fresh fruits and vegetables which is announced at the local newspaper and TV channels regularly; and overseas students are not offered food at places where overseas students accommodate, which gives rise to eat outside regularly. Managers at the municipalities and at the Ministry of Health are strongly suggested to be in charge of the health issue throughout the country since both local people, tourists and the overseas students from all over the world deserve to live in a clean country and buy everything not containing any drug residue. Community health and neighborhood sustainability can be improved by maintaining strong cooperation with urban planners and health professionals (Paine and Thompson, 2017). Governance of the drugs causing residue should be under the Ministry of Health and producers should be offered these kinds of drugs in a very limited way and the controls of their products should be carried out in a more strict way. Similarly, overseas students are not offered a health insurance by their universities. They need to pay money to get help from the health system. Also, most of the overseas students and doctors have got language as an impediment. They cannot communicate well in English, which is an international language most of the students know, to solve the health problem. It is also emphasized that most of the doctors, especially at the state hospitals, even do not cure the overseas students but ask them to come their afternoon sessions at the private hospital the doctor also works for, which means to pay extra money to the state hospital doctor at the private hospital. The foundation of strong advisory system, a well-managed counseling service, the health insurance, the language problem with the doctors and the irregularities at the health system in $\mathrm{NC}$ are the identified barriers for the overseas students which need to get close attention by the higher education providers, education and health system planners and politicians.

The proposed managerial model on managing students' welfare: Teaching staff in universities in NC mostly has a tendency to arrange classes according to the work-schedules of the students especially when the group is small. Observing that most of the students need to work to finance their studies and make their and their families living, some of the teaching staff has a tendency to arrange the lesson time due to the work-schedules of the students. This kind of tendency is beneficial for the students, but there is a danger in this since most of the students need to finance themselves. Their financing themselves means that they need to work. It is suggested that their work-conditions are well organized with a regulation. Therefore, they can be able follow their studies easily and comfortably. They need to be free enough to contribute their academic skills. It is observed that married families with a child and/or children are increasing day-by-day in 
$\mathrm{NC}$, they choose to live in $\mathrm{NC}$ and number of married couples with children is increasing sharply. Quality of human factors contributes to human satisfaction, which is the primary driver for intentional organizational outcomes (Bodet, 2006). Politicians, education planners and higher education providers need to make sure that no one is being left behind. Especially, children need to live under healthy conditions, are fed enough and take the necessary education. It is strongly suggested to identify the overseas students who have children with them, identify their needs and meet their most important needs, such as health, education and food based needs.

The proposed managerial model on managing being worldwide: Having lower levels of English language proficiency as well as graduating and working within the same university has been considered as an impediment since they provide a cycle, but may not guarantee quality. Getting higher level of English language proficiency is a kind of guarantee of international development for the overseas students, especially who desire to work internationally. Others desiring not to work internationally still may need to have higher level of English proficiency in order to find better professional opportunities. The overseas students' proficiency in English language entering university in Australia has been under consideration since overseas students are officially compulsory to fulfill such kind of requirement (Coley, 1999). A study confirms that international young students with lower levels of English proficiency studying in the US context have higher level of perceived discrimination than the local students have (Poyrazli and Lopez, 2007). It seems important to improve the level of English language proficiency the overseas students have. The higher education providers are highly suggested to search for the reasons why overseas students English language proficiency are not very high and take the necessary steps regarding the issue. On the other hand, graduating and working at the same university has found to be an impediment. In order to overcome this, academicians' exchange program has been strongly suggested to establish among universities in NC. This kind of system would promote cooperation among the universities, contribute to their professional development, manage their research activities and be familiar with the teaching system at other universities (Erden, 2014) and/or prevent teaching staff to arrange classes according to the working times of the students. Such kind of system for having highly improved English language proficiency and academicians' exchange program would also increase the quality of the teaching and researching activities mainly, which would make the universities in $\mathrm{NC}$ to be recognized world-wide since each student from each country would represent their university world-wide. Being worldwide requires being qualified effectively. The customers relate factors impeding quality with the restricted size of resources, the excessive workload, the insufficient trainings or the lack of orientation. Additionally, the quality initiatives has impacted quality of service which has positive relationship with how the senior managers approach to the quality of service operations as well as how senior managers approach to the middle and first line managers (Soltani, Liao, Singh and Wang, 2010). Similarly, service quality indicators are called the provision of the service, efficiency of the staff, impression, amount of money, perceptible in touch, easiness of the advanced payment, safety and quality in keeping information secret, using technology and having reliable technology (Ganguli and Roy, 2013). Quality of the service requires direct control over service delivery, which strongly depends on providing high quality performance (Iwaarden and Valk, 2013). Overseas students are offered educational services primarily required to be qualified enough. Satisfaction has been primarily influenced by physical environment and word of mouth communications (Alexandria, Zahariadis, Tsorbatzoudis and Grouios, 2004).

To conclude, overseas students grow, mature and learn in a foreign context. There are series of complexities they experience and need to overcome successfully. Dealing and overcoming such kind of complexities lead them to grow, learn and find their identity through their maturation process. Also, they learn to develop themselves. They face difficulties basically regarding educational environment, different culture and community they are immersed in. Personal, pedagogical and psychological adaptation gives rise to have support, cooperation and contact with the necessary sectors to organize and manage appropriately since higher education providers and education planners are required to cooperate with various sectors to overcome the impediments the overseas students' experience.

\section{REFERENCES}

[1] Alexandria, K., Zahariadis, P., Tsorbatzoudis, C. and Grouios, G. (2004). An empirical investigation of the relationships among service quality, customer satisfaction and psychological commitment in a health club context. European Sport Management Quarterly, 4(1), 36-52. Doi: http://dx.doi.org/10.1080/16184740408737466.

[2] Anderson, L.E. 1994. A new look at an old construct: Cross-cultural adaptation. International Journal of Intercultural Relationships, 18(3), 293-328. Doi: https://doi.org/10.1016/0147-1767(94)90035-3.

[3] Billett, S. (2010). The perils of confusing lifelong learning with lifelong education. International Journal of Lifelong Education: The Future of Lifelong Learning, 29(4), 401-413. Doi:

http://dx.doi.org/10.1080/02601370.2010.488803

[4] Bodet, G. (2006). Investigating customer satisfaction in a health club context by an application of the tetraclasse model. European Sport Management Quarterly, 6(2), 149-165. Doi: 
http://dx.doi.org/10.1080/16184740600954148

[5] Brooks, R. and Everett, G. (2008). The impact of higher education on lifelong learning. International Journal of Lifelong Education, 27(3), 239-254. Doi: http://dx.doi.org/10.1080/02601370802047759

[6] Byram, M. (2003). On being 'bicultural' and 'intercultural'. In Intercultural experience and education, ed. G. Alred, M. Byram, and M. Fleming, 50-66. Clevedon, UK: Multilingual Matters.

[7] Coley, M. (1999). The English language entry requirements of Australian universities for students of non-English speaking background. Higher Education Research and Development, 18(1), 7-17. Doi: http://dx.doi.org/10.1080/0729436990180102

[8] Dearmond, M., M. (1988). International health. Journal of American College Health: International Students Health, 36(6), 36. Doi:

http://dx.doi.org/10.1080/07448481.1988.9939023

[9] Ebbin, I., J. and Blankenship, E., S. (1986). A longitudinal health care study: International versus domestic students. Journal of American College Health, 34(4), 177-182. Doi: http://dx.doi.org/10.1080/07448481.1986.9939634

[10] Ebbin, A., J. and Blakenship, E., S. (1988). Stress-related diagnosis and barriers to health care among foreign students: Results of a survey. Journal of American College Health, 36(6), 311-312. Doi:

http://dx.doi.org/10.1080/07448481.1988.9939025

[11] Erden, H. (2014). Educational professionals' perceptions regarding impediments and frequencies in initial teacher training. Hacettepe University Journal of Education, 29(4), 60-74. Retrieved from http://www.efdergi.hacettepe.edu.tr/makale_goster.php?id $=45$

[12] Furnham, A. 2004. Foreign students' education and culture shock. The Psychologist 17(1), 16-19. Retrieved from http://thepsychologist.bps.org.uk/volume-17/edition-1/fore ign-students-education-and-culture-shock

[13] Ganguli, S., and Roy, S., K. (2013). Conceptualisation of service quality for hybrid services: A hierarchical approach. Total Quality Management and Business Excellence, 24(9-10), 1202-1218. Doi: http://dx.doi.org/10.1080/14783363.2013.814293

[14] Georgiou, M. and Savvidou, C. (2014). 'Either you know Greek or too bad for you': International students' intercultural experiences in Cyprus. Intercultural Education, 25(1), 41-54. Doi:

http://dx.doi.org/10.1080/14675986.2014.883190

[15] Gill, S. (2007). Overseas students' intercultural adaptation as intercultural learning: A transformative framework. Compare: A Journal of Comparative and International Education, 37(2), 167-183. Doi: http://dx.doi.org/10.1080/03057920601165512

[16] Gribble, C. and Blackmore, J. (2012). Re-positioning Australia's international education in global knowledge economies: Implications of shifts in skilled migration policies for universities. Journal of Higher Education Policy and Management, 34(4), 341-354. Doi: http://dx.doi.org/10.1080/1360080X.2012.689181
[17] Gu, Q, Schweisfurth, M, and Day, C. (2010). Learning and growing in a foreign context: Intercultural experiences of international students. Compare: A Journal of Comparative and International Education, 40(1), 7-23. Doi: $10.1080 / 03057920903115983$

[18] Hyun, J., Quinn, B., Madon, T. and Lustig, S. (2007). Mental health need, awareness, and use of counselling services among international graduate students. Journal of American College Health, 56(2), 109-118. Doi: http://dx.doi.org/10.3200/JACH.56.2.109-118

[19] Iwaardeni J., V. and Valk, W., V., D. (2013). Controlling outsourced service delivery: Managing service quality in business service triads. Total Quality Management and Business Excellence. Relationship Quality and Customer Satisfaction in Service Contexts, 24(9-10), 1046-1061. Doi: http://dx.doi.org/10.1080/14783363.2013.776766

[20] Kim, M., S. (2005). Culture-based conversational constraints theory: Individual-and cultural- level analyses. In Theorizing about intercultural communication, ed. W.B. Gudykunst, 93-118. Thousand Oaks, CA: Sage.

[21] King, P.M., and M. Baxter Magolda. (2005). A developmental model of intercultural maturity. Journal of College Student Development, 46(6), 571-592. Doi: $10.1353 /$ csd.2005.0060

[22] Leung, C., Pe-Puab, R., and Karnilowicz, W. (2006) Psychological adaptation and autonomy among adolescents in Australia: A comparison of Anglo-Celtic and three Asian groups. International Journal of Intercultural Relations, 30(1), pp. 99-118. Doi: https://doi.org/10.1016/j.ijintrel.2005.09.002

[23] Li, A., and Gasser, M. (2005). Predicting Asian international students' sociocultural adjustment: A test of two mediation models. International Journal of Intercultural Relations 29(5), 561-76. Doi: https://doi.org/10.1016/j.ijintrel.2005.06.003

[24] Lincoln, Y., S. and Guba, E., G. (1985). Naturalistic inquiry. Thousand Oaks, California: Sage Publications.

[25] Miles, M., and Huberman, M. (1994). Qualitative data analysis. Beverly Hills: Sage Publications.

[26] Nunan, D. (1999). Research methods in language learning. (8th ed.). Cambridge: CUP.

[27] Mori, S. (2000). Addressing the mental health concerns of international students. Journal of Counselling and Development 78(2), 137-44. Doi: 10.1002/j.1556-6676.2000.tb02571.x

[28] Nyland, C., Mewett, H., F. and Marginson, S. (2010). The international student safety debate: Moving beyond denial. Higher Education Research and Development, 29(1), 89-101. Doi: http://dx.doi.org/10.1080/07294360903277364

[29] Nyland, C., Mewett, H., F., Marginson, S., Ramia, G., Sawir, E., and Smith, S. (2009). International student-workers in Australia: A new vulnerable workforce. Journal of Education and Work, 22(1), 1-14. Doi: http://dx.doi.org/10.1080/13639080802709653

[30] Obeng-Odoom, F. (2012). Far away from home: The housing question and international students in Australia. 
Journal pf Higher Education Policy and Management, 34(2), 201-216. Doi: http://dx.doi.org/10.1080/1360080X.2012.662744

[31] Oxford Dictionaries. (n.d). Definition of impediments in English. Retrieved from https://en.oxforddictionaries.com/definition/impediment

[32] Paine, G., and Thompson, S. (2017). What is a health sustainable built environment? Developing evidence-based healthy built environment indicators for policy-makers and practitioners. Planning, Practice and Research. 1-19. Doi: http://dx.doi.org/10.1080/02697459.2017.1378972

[33] Paltridge, T, Mayson, S, and Schapper, J. (2010). The contribution of university accommodation to international student security. Journal of Higher Education Policy and Management, 32(4), 353-364. Doi: http://dx.doi.org/10.1080/1360080X.2010.491109

[34] Paulston, C.B. (1992). Biculturalism: Some reflections and speculations. In Sociolinguistic perspectives on bilingual education, ed. C.B. Paulston, 116-30. Clevedon, UK: Multilingual Matters.

[35] Patton, M., Q. (2002). Qualitative research and evaluation methods (3rd ed.). Thousand Oaks, CA: Sage Publications.

[36] Poyrazli, S. and Lopez, M., D. (2007). An exploratory study of perceived discrimination and homesickness: A comparison of international students and American students. The Journal of Psychology: Interdisciplinary and Applied, 141(3), 263-280. Doi: http://dx.doi.org/10.3200/JRLP.141.3.263-280

[37] Robertson, M., Line, M., Jones, S, and Thomas, S. (2000). International students, learning environments and perceptions: A case study using the Delphi technique. Higher Education Research and Development, 19(1), 89-102. Doi:

http://dx.doi.org/10.1080/07294360050020499

[38] Samuelowicz, K. (1987). Learning problems of overseas students: Two sides of a story. Higher Education Research and Development, 6(2), 121-133. Doi: http://dx.doi.org/10.1080/0729436870060204

[39] Soltani, E., Liao, Y,. Y., Singh, A. and Wang, W., Y. (2010).
Managing service quality: The managers' orientations and their consequences- case study evidence of current practice. Total Quality Management and Business Excellence, 21(6), 673-685.

Doi: http://dx.doi.org/10.1080/14783363.2010.483097

[40] Sousa, R., Amorim, M., Pinto, G., M., and Magalhães, A. (2016). Multi-channel deployment: A methodology for the design of multi-channel service processes. Production Planning and Control: The Management of Operations, 27(4), 312-327. Doi: http://dx.doi.org/10.1080/09537287.2015.1125031

[41] Thurber, C., A. and Walton, E., A. (2012). Homesickness and adjustment in university students. Journal of American College Health, 60(5), 415-419. Doi: http://dx.doi.org/10.1080/07448481.2012.673520

[42] Ziguras, C. and Law, S., F. (2006). Recruiting international students as skilled migrants: The global 'skills race' as viewed from Australia and Malaysia. Globalisation, Societies and Education. Brain Drain, Brain Gain and Brain Circulation, 4(1), 59-76. Doi: http://dx.doi.org/10.1080/14767720600555087

[43] Zhou, Y., Jindal-Snape- D., Topping, K. and Todman, J. (2008). Theoretical models of culture shock and adaptation in international students in higher education. Studies in Higher Education, 33(1), 63-75. Doi: http://dx.doi.org/10.1080/03075070701794833

[44] Ward, C., and Kennedy, A. (1993). Where's the 'culture' in cross-cultural transition: Comparative studies of sojourner adjustment. Journal of Cross-cultural Psychology 24(2), 221-49. Doi: https://doi.org/10.1177/0022022193242006

[45] Ward, C., and Kennedy, A. (1999). The measurement of sociocultural adaptation. International Journal of Intercultural Relations 23(4), 659-77. Retrieved from https://www.researchgate.net/profile/Colleen_Ward2/publi cation/223159146_The measurement_of_sociocultural_ad aptation/links/5790339f308ae4e917cff3̄d0 $\overline{3}$.pdf

[46] Zohrabi, M. (2013). Mixed method research: Instruments, validity, reliability and reporting findings. Theory and Practice in Language Studies, 3(2), 254-262. Doi: $10.4304 /$ tpls.3.2.254-262 